\title{
Conceptualising Digital Transformation in SMEs: An Ecosystemic Perspective
}

\author{
Claudia PELLETIER, DBA \\ Assistant Professor \\ Institut de recherche sur les PME (INRPME) \\ École de gestion \\ Université du Québec à Trois-Rivières (UQTR) \\ e-mail: Claudia.Pelletier@uqtr.ca
}

\author{
L. Martin CLOUTIER, Ph.D. \\ Professor \\ Management and Technology Department \\ École des sciences de la gestion (ESG) \\ Université du Québec à Montréal (UQAM) \\ e-mail: cloutier.martin@uqam.ca
}

\begin{abstract}
Purpose - Supported by a service ecosystem that is increasingly immersed into the digital transformation, SMEs have access to turnkey IT applications, which may come free of charge but not free of concerns, given relational aspects this implies. The objective of the study is to explore a group conceptualisation and perceptions pertaining to IT issues within an ecosystem that includes three subgroups: entrepreneurs, IT professionals and socioeconomic support professionals.

Design/Method/Approach - Using group concept mapping (GCM), a bottom-up and participatory mixed methods-based approach, a concept map was estimated based on a list of items to define the dimensions pertaining to issues and challenges of adoption and use of turnkey IT applications in SMEs with fewer than 20 employees. Perceptions measures of relative importance and feasibility were obtained by subgroups.

Findings - The relative importance and relative feasibility measures for the seven clusters identified on the concept map indicate significant statistical differences in ratings among the subgroups. A discussion on the importance of relational capital in addressing challenges of digital transformation in SMEs is developed.

Originality/Value - Results highlight important differences concerning key dimensions in the adoption and use of IT from the perspective of three subgroups of actors within the ecosystem. First, the results stress the need to develop a shared understanding of IT challenges. Second, they suggest policymakers could use these conceptual representations to further develop and strengthen the IT-related support agenda for SMEs, especially the smaller ones (e.g. training programs, business support and coaching initiatives, etc.).
\end{abstract}

\section{Keywords}

Digital transformation; IT challenges; IT adoption and use; SMEs; Business ecosystem; Service-dominant (S-D) logic; Relational capital; Turnkey IT applications; Professional business support; Group concept mapping. 


\section{Conceptualising Digital Transformation in SMEs: An Ecosystemic Perspective}

\author{
Claudia PELLETIER, DBA \\ Assistant Professor \\ Institut de recherche sur les PME (INRPME) \\ École de gestion \\ Université du Québec à Trois-Rivières (UQTR) \\ e-mail: Claudia.Pelletier@uqtr.ca
}

\author{
L. Martin CLOUTIER, Ph.D. \\ Professor \\ Management and Technology Department \\ École des sciences de la gestion (ESG) \\ Université du Québec à Montréal (UQAM) \\ e-mail: cloutier.martin@uqam.ca
}

\section{Introduction}

Based on the need to embark on the digital transformation and improve business competitiveness on the world stage (OECD, 2017), small and medium-sized enterprises (SMEs) - less than 20 employees, represent more than $85 \%$ of all businesses in Canada are under pressure to adopt and use information technology (IT) more intensively (Innovation, Science and Economic Development of Canada, 2019). The ensuing prevailing discourse carries with it the notion that certain types of IT have become more accessible to SMEs, user-friendly and inexpensive. Although they represent a means to compensate for SMEs' limited internal resources (human, material and financial) (Pelletier and Raymond, 2017), turnkey IT applications adoption and use are also presented to suggest a reduction in the management process complexity, as well as more fruitful customer, supplier and business relationships. According to some observations, it is even possible the compensation for lack resources is the sole motivation for the use of IT, including turnkey IT applications (Street, Gallupe and Baker, accepted). Indeed, SMEs have access to turnkey IT applications in support of business functions, such as marketing (e.g., platforms for e-commerce, including social media applications); finance and accounting (e.g. open source software or mobile secure payment solutions) or human resources (e.g., collaborative tools, such as videoconferencing, shared calendars and instant messaging). Although they may represent an undeniable advantage in this context, turnkey IT applications can either be completely free or pay per use as they are based on a serviceoriented architecture (SOA) accessible over the Internet (Bradley, Pratt, Byrd and Simmons, 2011). 
As a means to initiate and support the digital transformation among SMEs, turnkey IT applications, including their infrastructure, are designed and developed by IT professionals. Yet, in parallel to entrepreneur turnkey IT adoption and use and the growing specialised service offers to SMEs on the part of IT professionals, socioeconomic support professionals are also called upon and mobilised to offer support, training, and expand their service range (Kilubi and O'Regan, 2016; Thorpe, Holt, Macpherson and Pittaway, 2005), in the area of digital and innovation to SMEs (Innovation, Science and Economic Development of Canada, 2019).

Hence, the use of expressions such as 'digital transformation' and 'digital strategy' are increasing in the business ecosystem as well as in socioeconomic and political arenas (OECD, 2017). Nevertheless, these 'new' expressions, which definition remain polysemous, often lead to highly uneven representations of issues experienced among actors in ecosystems (Amiri, Cavusoglu and Benbasat, 2015; Oney, Özdinç and Çavuşyan, 2018). Moreover, adding to challenges of divergent representations of this phenomenon among actors, the imperative to engage into the digital transformation is presented to SMEs in ways which emphasises the urgency of large-scale and quick actions. However, as useful and necessary as they may appear to be a priori, the use of IT, be it turnkey applications or not, pose several important challenges to SMEs: (1) The fair and realistic IT needs assessment and, as a result, the coherence of choices with respect to business objectives (e.g. IT strategic alignment) (Chan and Reich, 2007; Pelletier and Raymond, 2017); (2) The need for skills and competencies required to ensure the management of newly implemented IT (Neirotti, Raguseo and Paolucci, 2018); (3) The consideration of a growing complexity in the ecosystem (Levy, Powell and Yetton, 2011), including the establishment and management of relationships with IT professionals and service providers such as socioeconomic support professionals (e.g. management professionals in public organisations) (Vargo and Lusch, 2016a).

Despite growing compatibility and interoperability of turnkey IT products and services offered (Bradley et al., 2011), actors involved might not hold common or shared perceptions regarding issues of IT adoption and use in a business context (Preston and Karahanna, 2009; Reich and Benbasat, 2000). This problem ought to be investigated to help entrepreneurs and SMEs, and inform and guide effective digital transformation 
interventions in collaboration with IT professionals and socioeconomic support professionals (Besson and Rowe, 2012; Gregory, Keil, Muntermann and Mähring, 2015). In other words, to better exploit the complementary nature of IT resources and competencies, many actors are currently expressing the need for clearer definitions and guidelines given the emerging complexity the digital transformation entails.

This paper examines issues and challenges in the adoption and use of turnkey IT applications by SMEs from a relational and ecosystemic perspective that is founded on a service-dominant (S-D) logic (Tsujimoto, Kajikawa, Tomita and Matsumoto, 2018; Vargo and Lusch, 2008, 2016a). Hence, the notion of representation based on the concept of sensemaking seems promising (Weick, 1995). The objective of the study is to explore the group representations and perceptions pertaining to IT and digital transformation issues within an ecosystem that includes subgroups of entrepreneurs, IT professionals and socioeconomic support professionals. The research question is: How do three subgroups of actors interacting in a service ecosystem primarily dedicated to SMEs collectively perceive and assess challenges of digital transformation when adopting and using turnkey IT applications? As a methodological framework, the group concept mapping (GCM) is employed (Cloutier and Spooner, 2016; Kane and Rosas, 2018; Rosas, 2017; Trochim, 2017). This study provides results interpreted through a relational-based view perspective concerning digital transformation in SMEs (Dyer and Kale, 2007). In particular, regarding challenges encountered in this context. Given the growing interdependence between subgroups of actors within ecosystems and the need for interconnecting respective forces and competencies in this context, the main contribution of the research is a better understanding of boundaries and relationships among entrepreneurs, IT professionals, and socioeconomic professionals providing support services to SMEs (Roundy and Fayard, 2018).

The remainder of the paper is organised as follows. The background is presented in section 2. The GCM method is detailed in section 3, followed by the results in section 4 . The discussion in section 5 examines how divergences and convergences in perception regarding the challenges of the digital transformation of SMEs among the three subgroups of actors lead to a situation where other important issues are emerging. For example, concerning the need for better-aligned support actions among these actors regarding 
services and programs currently offered to SMEs. Implications for practice and theory and a conclusion complete the paper.

\section{Background}

Digital transformation strategy has been defined as "a central concept to integrate the entire coordination, prioritisation, and implementation of digital transformation within a firm" (Matt, Hess and Benlian, 2015, p. 339). Consequently, interaction, communication, collaboration, within the firm, are central points of interests (Oney et al., 2018). With regard to access and/or implementation of novel technologies in particular, external relationships and partnerships are also significant, especially for SMEs (Kilubi and O'Regan, 2016; Neirotti et al., 2018).

The approach taken in this paper focuses on the "who", i.e. actors within and around the organisation, their values, beliefs, attitudes, communications, as well as their understanding of issues experienced (Reich and Benbasat, 2000). Consistent with specificities of the entrepreneurial context, SMEs and their business environments, the reasons for this approach are: (1) Its coherence with the definition of IS/IT-enabled organisational transformation, which is "a global phenomenon in which psychological, socio-cognitive, sociotechnical, economic and political considerations intertwine" (Besson and Rowe, 2012, p. 105); (2) The attention given to actors' cognition which is relevant to a service-dominant logic (S-D) approach in an ecosystem that relies on actor-to-actor (A2A) orientation for value creation (Vargo and Lusch, 2011); (3) Its focus on individuals, and their conceptualisations, behaviours and relationships (Dulipovici and Robey, 2013), including the influence of their environment on all of these elements (Weick, 1995).

\subsection{Social and relational dimensions of digital transformation in SMEs}

Digital transformation changes the way of doing business, and in particular how enterprises as well as individuals and groups operate, communicate and create value through IT (Oney et al., 2018). In such a context, individuals create a representation of this transformation "to construct a cognitive framework for their interpretation of reality. However, an individual's thoughts do not form in isolation, but rather are based on collectively shared images of objects" (Dulipovici and Robey, 2013, pp. 106-107). The social dimension of 
the process of digital transformation is thus revealed, an aspect of sensemaking that is easy to forget (Weick, 1995). In doing so, the need for connecting complementary forces, to support entrepreneurship and SMEs, has been expressed, especially given challenges of digital age (Roundy and Fayard, 2018). There are several reasons for this. First, digital transformation in SMEs addresses psychological inertia at the individual level (e.g. entrepreneurs), sociotechnical inertia at the group level (e.g. IT professionals), and economic and political inertia at the systemic level (e.g. socioeconomic support professionals) (Besson and Rowe, 2012). Second, the specific and emerging IT needs result in the increased interdependence of varied and more frequent new relationships among actors working together (Kelly and Scott, 2012; Oney et al., 2018). Third, the very high possibility critical resources or key technological activities for the enterprise and its operations stand outside organisational boundaries (Kilubi and O'Regan, 2016), especially regarding resources required as input into innovation and services offered (Barrett, Davidson, Prabhu and Vargo, 2015). Fourth, the need to define the respective boundaries of action for all actors involved, including conditions under which activities and exchanges occur (Thorpe et al., 2005; Vargo and Lusch, 2011).

Given the multidimensionality and the growing complexity of digital transformation (Matt et al., 2015), SMEs are thus increasingly in need of professional IT resources as well as support from socioeconomic development organisations and institutions (Gregory et al., 2015; Kelly and Scott, 2012). Because novel technologies are often unknown to enterprises, these specific resources are accessible in the business environment and on the Internet (Kilubi and O'Regan, 2016). The effective management of IT financial aspects, their use, and the changes in value creation and structures they cause (Matt et al., 2015), however, requires some attention be given to relational (Dyer and Kale, 2007), social (Reich and Benbasat, 2000), and cognitive dimensions (Tan and Gallupe, 2006). This is because these resources support the development of new behaviour (Zollo, Bettinazzi, Neumann and Snoeren, 2016), as much as key IT competences in SMEs, jointly with IT professionals and socioeconomic actors in the ecosystem (Pelletier and Raymond, 2017). To summarise, with regard to IT and digital transformation issues, SMEs need to develop and/or access strategic technology partnership capabilities which form a complex set of capabilities related to: (1) Complementarity; (2) Learning and exploitation; 
(3) Organisational elements; (4) Network, alliance, and partnership, as well as (5) Technological, innovative, and internal expertise (Kilubi and O'Regan, 2016, pp. 225-226).

\subsection{Value cocreation for digital transformation in SMEs}

Given issues experienced by entrepreneurs and in SMEs, the accelerating digital transformation places IT professionals in front of two challenging situations regarding social interactions among each other and with other actors. First, the need to develop managerial and business competences may not be aligned with personal and social skills which are inherently more technical in nature (Amiri et al., 2015). Second, attitudes and behaviours that could support the specific interests of many subgroups, such as entrepreneurs or socioeconomic professionals, may not be that well supported given IT professionals seldom favour exchanges and/or relationships with other subgroups in the ecosystem (Gottschalg and Zollo, 2007; Tan and Gallupe, 2006). Moreover, given an increasingly actor-to-actor and service-oriented perspective where "it's all B2B" (Vargo and Lusch, 2011), IT professionals are called upon to design and develop IT applications of commercial value as much for them, as for their customers. From a learning perspective, this situation refers to the development of a type of co-specialisation concerning information and know-how between IT professionals and users with the underlying idea of enhancing the lived common experience (Dyer and Kale, 2007). This also corresponds to the "value cocreation framework" where service is defined as a "process of using one's resources for the benefit of another, rather than an output (i.e. an intangible product)" (Ng and Vargo, 2018, p. 518).

On the one hand, and because mind shifts and cultural changes are required, digital transformation is generally costly, time-consuming and risky (Oney et al., 2018). As for entrepreneurs and SMEs, IT professionals need a complex set of capabilities that implies skills and aggregated knowledge through educated organisational processes (Kilubi and O'Regan, 2016). One the other hand, with respect to socioeconomic support professionals, particularly the ones focused on financial services, their client needs change and evolve rapidly in response to digital transformation pressures. Given the rising strategic importance of IT for SMEs (Celuch, Murphy and Callaway, 2007; Pelletier and Raymond, 
2017), this particular subgroup of actors may not feel prepared enough to offer this emerging or higher knowledge-based intervention (OECD, 2017; Roundy and Fayard, 2018; Thorpe et al., 2005). Indeed, as documented, it is through shared understanding among actors the 'positive' break-up of functional boundaries regarding learning and IT in the SME context can occur (Street et al., accepted). This includes the clarification of existing guidelines to better adapt existing programs and socioeconomic support interventions to the emerging digital business context and its ecosystem (Gregory et al., 2015).

Similarly to entrepreneurs and SMEs, the social aspects surrounding the work of IT professionals and socioeconomic support professionals interacting with other actors are also crucial to help connect their respective resources and expertise (Dyer and Kale, 2007). This explains why, from an ecosystemic perspective, actual inputs and requirements may sometimes differ from the current discourse about SMEs needing to engage in a 'Digital agenda' and rush to address the urgency of the 'Digital transformation'(Roundy and Fayard, 2018).

\subsection{Business ecosystem or service ecosystem? Adopting the $S$-D logic}

Tsujimoto et al. (2018) have identified five types of business ecosystems: a) Digital; b) Complementary (sub-industry); c) Supplier; d) Business group (M\&A); and e) Global professional human networks. Although their definitions may vary, researchers focus on two main elements, namely actors/players concerned (business player networks), their behaviour and the mechanisms acting in the background (network dynamics and patterns). They also distinguish these networks from another type of ecosystem called "multi-actor network" that includes "entrepreneurs and private investors, innovators who are outside of company pipelines, users/user communities, governmental bureaucrats/policy makers, and consortiums" (Tsujimoto et al. (2018, p. 6). Based on this categorisation, the five business ecosystems are actually components of the second type of ecosystem introduced. This broadens the composition of the group/network formed as well as distinguish different types of relationships held among their members.

From Vargo's and colleagues work over the last ten years, the S-D logic orientation is based on networks of actors involved in a given system (here the SMEs support service 
ecosystem). Thus, the behaviours and relationships these actors establish make possible the joint resource integration, rather than the maintenance of a more limited producer/consumer relationship (Tsujimoto et al., 2018). It is through the exchange of IT resources and specific skills and knowledge which come along with them, that various actors (entrepreneurs, managers, IT professionals, specialised stakeholders, consultants, etc.) build value as part of a cocreation process (i.e. the "value cocreation framework") (Ng and Vargo, 2018).

What precedes also means that the S-D logic applied to digital transformation goes beyond the microeconomic perspective of the traditional business ecosystem of customers, suppliers and other stakeholders with hierarchical or strictly complementary relationships (Vargo and Lusch, 2011, 2016b). Moreover, a focus on organisational actors makes possible the examination of longer-term IT-related issues (Dulipovici and Robey, 2013; Reich and Benbasat, 2000). To do this, actors can rely on an increased role for IS/IT (Besson and Rowe, 2012), or new behaviours and service innovations by actors involved, either at the development or at the deployment phases (Barrett et al., 2015). Indeed, because digital transformation implies a S-D logic (Vargo and Lusch, 2008), developing, refining and implementing adequate digital transformation calls for new roles from all actors, that is, entrepreneurs, IT professionals and socioeconomic support professionals (Fujita, Vaughan and Vargo, 2018; Oney et al., 2018). Thus, all actors involved ought to (re)evaluate their exchange modes given resource integration, including the way they manage multiple actors in a "real" service ecosystem (Vargo and Lusch, 2016a). In other words, a context such as a service ecosystem should be based on "relatively self-contained, self-adjusting system of resource-integrating actors connected by shared institutional arrangements and mutual value creation through service exchange" (Ng and Vargo, 2018, p. 518). To do this, the exploration of shared ideas (Tan and Gallupe, 2006), common interests (Gottschalg and Zollo, 2007), shared languages, including terminology used by various actors (Amiri et al., 2015; Preston and Karahanna, 2009), symbols, institutions and technology that interface with the actor needs (Vargo and Lusch, 2011) as well as dimensions of IS-enabled organisational transformation which relates to inertia and/or socio-technical path dependencies is key (Besson and Rowe, 2012). 
In a nutshell, the digital transformation from a service ecosystem adopting an S-D logic orientation is based on actors not fundamentally different, but who exchange skill and knowledge resources of various kinds to meet specific needs (Fujita et al., 2018). We thus no longer refer to resource production/consumption, but to the resource integration between organisations during exchanges whose coordination is based on "rules of the game" shared by the actors (Vargo and Lusch, 2016a). This supports a complex vision of the digital transformation process that begins with humans in relation to each other and not exclusively based on technological artefacts (Besson and Rowe, 2012; Dyer and Kale, 2007). Given this, the ecosystem of interest is based on the S-D logic of a service/multiactor ecosystem (Tsujimoto et al., 2018).

\subsection{Making sense of digital transformation}

On the one hand, the emergence and intensification of the use of IT for digital transformation, and the shift from a traditional "producer/consumer" ecosystem (e.g. business ecosystem) has become more challenging for SMEs (Neirotti et al., 2018). One the other hand, the entrepreneur wants to ensure business success and is strongly encouraged by public and support organisations to initiate a rapid "digital transformation", as well as to elaborate a deliberate "digital strategy" (OECD, 2017). Based on an increased use of IS/IT that involves different opportunities for innovation, including for service innovation (Barrett et al., 2015), organisational transformation is "understood as a process that engenders a qualitatively different organization" (Besson and Rowe, 2012, p. 103).

In an actor-to-actor (A2A) orientation for value creation (Vargo and Lusch, 2011), or

recently what has been named "entrepreneurial ecosystem" (Roundy and Fayard, 2018), offers a wide range of resources and services through IT professionals and various suppliers and professionals (e.g. service/multi-actor ecosystem). These represent major challenges given the growing strategic role of IT professionals, whether inside or outside the firm (Fujita et al., 2018; Tsujimoto et al., 2018). The situation has also evolved for socioeconomic support professionals who must reconsider their roles as well as the nature of their interventions (Roundy and Fayard, 2018; Thorpe et al., 2005).

Given what precedes, the use of representations based on the notion of sensemaking appears promising. Following seminal work on this concept (Weick, 1995), a sensemaking 
process, in such a context, raises four central questions regarding digital transformation challenges and IT-related issues, that is: (1) How do people construct this sense?; (2) What they construct?; (3) Why?, and (4) With what effects? In doing so, the sensemaking concept joins that of group representations within which "individuals create a representation of something (object, idea, concept, etc.) or someone (individual, group, etc.) to construct a cognitive framework for their interpretation of reality" (Weick, 1995, p. 4). Thus, sensemaking and representations are definitely contextually dependent activities, and that "may change not only the associated work practices but also the nature of the work itself" (Dulipovici and Robey, 2013, pp. 106-107). As pointed out since the 1990s by Reich and Benbasat (2000), these challenges and issues have not been examined on the semantic front where they refer to the common language shared between groups. This remains a major knowledge gap, because the terminology used by different groups has an impact on the language and perspective shared (or not) between actors (Amiri et al., 2015; Oney et al., 2018).

In such a context, sensemaking and representation concepts are useful to study as: (1) Cognitive elements, behaviours, and relationships (Dulipovici and Robey, 2013; Zollo et al., 2016); (2) Decision-making in a dynamic environment (Gottschalg and Zollo, 2007) and, finally (3) Similarities and differences displayed by entrepreneurs and SMEs managers in managerial, strategic and technological terms (Levy et al., 2011; Street et al., accepted).

\section{Methods}

Relevant for examining the collective or group aspects related to IT (Tan and Gallupe, 2006), the present study employs the GCM approach. The GCM is mixed methods-based (qualitative/quantitative) and employed with groups of participants (Rosas, 2017). It is used to highlight deliberate and unintentional learning systems, as well as complex interactions among underlying dimensions of business and service ecosystems, including those of very small enterprises/SMEs (Sutherland and Katz, 2005). The GCM method appears in the field of program planning and evaluation where it was first introduced (Kane and Rosas, 2018; Kane and Trochim, 2007), and has been applied to a host of other knowledge field areas (Trochim, 2017; Cloutier et al., 2017; Berg et al., 2018). 
The method uses multivariate statistical analyses to estimate conceptual representations, on the one hand, and to evaluate the perception, on the other hand, of issues associated with the digital transformation from the perspective of entrepreneurs, IT professionals, and socioeconomic support professionals. Table 1 summarises the five steps of the methodological framework conducted in the study.

Table 1.

Group Concept Mapping (GCM) Research Steps

\begin{tabular}{|c|c|c|c|c|}
\hline $\begin{array}{c}\text { Step } 1 \\
\text { Preparing for } \\
\text { GCM }\end{array}$ & $\begin{array}{l}\text { Step } 2 \\
\text { Generating } \\
\text { ideas }\end{array}$ & $\begin{array}{c}\text { Step 3: } \\
\text { Structuring items }\end{array}$ & $\begin{array}{c}\text { Step 4: } \\
\text { Estimating and } \\
\text { analysing concept } \\
\text { maps }\end{array}$ & $\begin{array}{c}\text { Step 5: } \\
\text { Interpreting } \\
\text { concept maps } \\
\text { and results }\end{array}$ \\
\hline $\begin{array}{l}\text {-Organise } \\
\text { research steps } \\
\text { - Recruit } \\
\text { participants } \\
\text { - Develop focus } \\
\text { prompt: } \\
\text { "Regarding } \\
\text { the use of } \\
\text { turnkey IT } \\
\text { applications } \\
\text { and electronic } \\
\text { platform, a } \\
\text { particular } \\
\text { issue for my } \\
\text { organisation } \\
\text { would be...." }\end{array}$ & $\begin{array}{l}\text { - Participant } \\
\text { group } \\
\text { discussion to } \\
\text { focus prompt } \\
\left(\mathrm{N}_{G D}=39\right) \\
\text { - Formalise } \\
\text { items } \\
(k=90)\end{array}$ & $\begin{array}{l}\text {-Complete } \\
\text { structured } \\
\text { contextual } \\
\text { survey } \\
\left(\mathrm{N}_{C}=32\right) \\
\text { - Sort drivers into } \\
\text { distinct piles } \\
\left(\mathrm{N}_{S}=60\right) \\
\text { - Rate drivers for } \\
\text { their "relative } \\
\text { importance" } \\
\left(\mathrm{N}_{R I}=60\right) \text { and } \\
\text { "relative } \\
\text { feasibility" } \\
\left(\mathrm{N}_{R F}=60\right)\end{array}$ & $\begin{array}{l}\text {-Use } \\
\text { multidimensional } \\
\text { scaling analysis } \\
\text { to generate dot } \\
\text { map } \\
\text { - Three group } \\
\text { debriefing } \\
\text { discussions with } \\
\text { use of } \\
\text { agglomerative } \\
\text { hierarchical } \\
\text { cluster and a } \\
\text { sense-making } \\
\text { discussion to } \\
\text { generate cluster } \\
\text { map }\left(\mathrm{N}_{D S}=12\right)\end{array}$ & $\begin{array}{l}\text { - Evaluate } \\
\text { results and } \\
\text { produce } \\
\text { collective } \\
\text { meaning from } \\
\text { conceptual } \\
\text { results and } \\
\text { contrasted } \\
\text { with the } \\
\text { literature }\end{array}$ \\
\hline
\end{tabular}

Note: Number of participants in group discussions $\left(\mathrm{N}_{G D}\right)$; Number of participants completed contextual survey $\left(\mathrm{N}_{C}\right)$; Number of participants who sorted items $\left(\mathrm{N}_{S}\right)$; Number of participants who rated items $\left(\mathrm{N}_{R}\right)$; Number of clusters in group debriefing discussion $\left(\mathrm{N}_{D S}\right)$

Step 1 Preparing for GCM was conducted with a steering committee established for the project. It included the research team and socioeconomic support professionals involved in delivering IT training for entrepreneurs and SMEs. The following tasks are accomplished: determine the focus prompt, fix the timeline and logistical planning, as well as identify participant profiles and the recruitment approach. The focus prompt is used by the steering committee with participants throughout the research steps as it casts the topic and the thread line around which ideas are formalised into items to produce results. As seen in Table 1, the focus prompt is: "Regarding the use of turnkey IT applications and electronic platform, a particular issue for my organisation would be ...". The selection criteria for participants 
were: (1) have a role in the ecosystem (either one of the following profile: entrepreneur in an SME of less than 20 employees; IT professional; socioeconomic support specialist); (2) have experienced or witness IT challenges and their applications in the context of small businesses, and (3) have an interest in participating to a group discussion (step 2) which is to generate ideas, as well as for subsequent GCM steps, but without the obligation to participate at all stages.

For Step 2 Generating ideas, using group discussions (GDs), taking the form of brainstorming sessions. Six (6) GDs of about 90 minutes each were held with $\mathrm{N}_{G D}=39$ participants. During GDs, participants were prompted to share ideas within the scope of the focus prompt. After ideas were collected and synthesised, a total of $k=90$ items were formalised and each one was attributed an identification number to help with traceability in empirical results analysis and display. Exact examples of ideas obtained during GDs formalised as items include (item identification number(s) in hard brackets): 'To use IT to develop my enterprise' [item 33]; 'To measure the impact of IT tools (e.g. ROI, sales, performance)' [item 90]; 'To link my expectations with the reality of apparent user-friendly IT turnkey platforms' [item 87]; 'To be better informed about available IT training'[item 55]; and 'To establish transparent communications between entrepreneurs and IT specialist about expectation and deliverables to avoid a deception'[item 80].

The Step 3, Structuring items, was conducted face-to-face with individual entrepreneurs, IT professionals and socioeconomic support professionals. Three tasks were completed by the entrepreneurs' subgroup. Task 1 included a short contextual survey. The survey consist of simple questions useful to determine the participant profile, background, and role within the ecosystem. For Task 2, participants were asked to sort the 90 -item deck of cards (business card format) provided to them into piles with the following instructions: (1) make a minimum of five piles of items (no upward limit on the number of piles); (2) put items into piles which contents appear closely related to each other (no other criterion, such as importance); (3) allocate items to one pile only; (4) make a pile of "1" item for the ones that appear unrelated to any other. When the sorting task is completed, participants are asked to name each pile based on the overreaching theme of the item set within it; and to write on a form the pile name and the item numbers that are in each one. The Task 3 included rating items on two 5-point Likert type scales to obtain perception measures of 
relative importance and relative feasibility $(1=$ not important $/$ not feasible, and $5=$ extremely important/extremely feasible). For this task, the rating data were also collected from $\mathrm{N}_{I T}=14$ IT professionals, and from $\mathrm{N}_{S S P}=14$ socioeconomic support professionals so that perception measures could be estimated for all three subgroups.

The Step 4 Estimating and analysing concept maps includes multivariate statistical estimations using the software CS Global MAX ${ }^{\circledR}$ (www.conceptsystems.com). First, the sort data collected from individual participants (Step 3, Task 2) are entered into the software and set up as individual square diagonal binary $(90 \times 90$ items $)$ similarity matrices of intersections among items - each item on the diagonal of the matrix is sorted with itself. The expression "similarity' refers to the similarity of idea sorted together into a pile. Second, each individual square diagonal binary similarity matrices for $N_{S}=32$ entrepreneurs are then summed across horizontally to yield the overall total square diagonal similarity matrix. An illustration of the structuration of the total square diagonal similarity matrix is shown in figure 1. For example, the matrix indicates that the item 1 (row 1) was sorted out 8 times by participants with the item 2 (column 2); and also, that the item 4 (row 4 ) was sorted out by participants 5 times with item 2 (column 2), and so on.

Figure 1.

Total Square Diagonal Similarity Matrix of Items Sorts by the Subgroup of Entrepreneurs $\left(N_{S}=32\right.$ entrepreneurs)

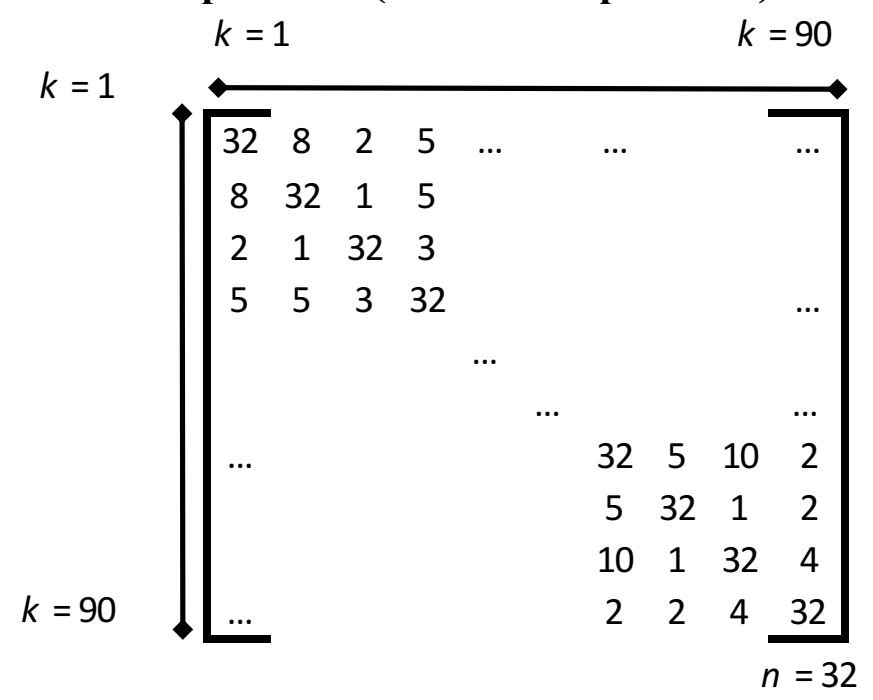

The total similarity matrix is analysed using non-metric multidimensional scaling analysis (MDS) (Kruskal and Wish, 1978) method to estimate the bidimensional $X-Y$ 
coordinates on the Euclidean plane. The set of numbered items, that forms the GCM dot map, which numbers correspond to one of the $k=90$ items in the set, is used to establish the GCM spatial structure. Measures of internal statistical reliability and validity were obtained and fall within the acceptable range established in GCM pooled studies ${ }^{1}$ (Rosas and Kane, 2012).

As part of the MDS estimation, it is possible to use the Euclidean distances among $X-Y$ coordinates to obtain a distance matrix of each item among them, and calculate anchoring and bridging measures which takes into account the frequency of item sorting together by the number of sorters (Kane and Trochim, 2007). From these estimations, an AnchoringBridging Index (ABI) can be obtained to help analyse the conceptual distance between clusters with respect to the level of agreement among participants in the study (Cloutier, Arcand, Laviolette and Renard, 2017). The interpretation is as follows. A cluster is considered an anchor in the concept map when the ABI is closer to " 0 ", and a bridge when the $A B I$ index is closer to " 1 ". In other words, there is a conceptual agreement among participants when the cluster is an anchor, and there is less conceptual agreement among participants when the cluster is a bridge (Kane and Trochim, 2007). Second, the $X, Y$ coordinates of each item in the set, which form the GCM dot map, estimated from the MDS method, and are used to conduct the agglomerative hierarchical cluster analysis (AHCA) using the Ward algorithm (Everitt, Landau, Leese and Stahl, 2011), so that non-overlapping clusters can be identified on the resulting group concept map for interpretation and use. This makes possible to overlay all numbered items onto the GCM dot map onto the concept map as shown in the results section.

Step 5 Interpreting concept maps and results takes the estimates from the Step 4 back to the steering committee supplemented with additional interested participants to determine and interpret the 'definitive' concept map. There are two reasons for this. First, participants

\footnotetext{
${ }^{1}$ The MDS produces the stress value (SV) $[0.17<0.29<0.34]$. Other internal validity tests were conducted and results obtained are within documented ranges (Rosas and Kane, 2012): Configurational similarity; R²; SV for Sample split-half-1; SV for Sample split-half-2; Individualto-individual sort reliability; Individual-to-total sort reliability; Individual-to-map reliability; Sample split-half total reliability; Sample split-half map reliability; Sample split-half total reliability. Overall, results obtained satisfy criteria established considered valid and reliable the in GCM research literature.
} 
are given the printout from the HCA starting from 12 down to 5 clusters. For example, the printouts include the list of items on a per cluster basis, showing at each iteration the merger between two clusters on the concept map. The role of the AHCA is to help determine the

spatial conceptual proximity between clusters of items in a strictly statistical sense using Euclidean distance measures. Second, participants debrief among them about the conceptual proximity of the proposed cluster merger and decide whether items on these clusters ought to be merged or not. The exercise was conducted with entrepreneurs' AHCA outputs of item sorts. During the group debriefing discussion, participants settled on a seven cluster representation. Given clusters are formed of items, and the HCA results reveal where they are located on the concept map, the scale results are averaged out for each item. It becomes possible to determine perceptions the three subgroups hold about the various themes each cluster represents, and to compare them. This step serves to establish external result validity. The estimated group concept map (representation) is used to analyse associated perceptions, using pattern matches and go-zones, from both a theoretical and a practical managerial perspective for the three subgroups (entrepreneurs; IT professionals and socioeconomic support professionals).

\section{Results}

This section includes two sets of results. The group concept map, that is the conceptualised representation by small business entrepreneurs, is described in section 4.1; and the relative importance and feasibility ratings, that is the comparative perception analysis in between subgroups of entrepreneurs, IT professionals, and socioeconomic support professionals are presented in section 4.2 .

\subsection{Entrepreneurs' conceptual framework}

The group concept map statistically estimated using the multivariate MDS and AHCA methods using the sort data obtained from entrepreneurs (Section 3, steps 4 and 5). The map contains seven (7) non-overlapping clusters on the Euclidean plane (Figure 2) where the $\mathrm{k}=90$ items are spatially distributed. The stress value, a measure of internal statistical reliability is 0.29 ; which is considered appropriate within the range expected in GCM pool 
studies $^{2}$ (Rosas and Kane, 2012). On the group concept map, each cluster comprises a number of items allocated based on AHCA results coupled with participants' input obtained during the debriefing session to identify the cluster names (section 3, Step 5). The clusters identified on the map (written in italics when referred to in the text) are: Digital Strategy at the centre; and reading clockwise from the north of the map, Understanding and Use; Competence Development; Services and Deliverables; Relational Capital; IT; Attitude and Behaviour; and Evaluation and support.

Figure 2.

\section{Group Concept Map Based on MDS and AHCA Estimates}

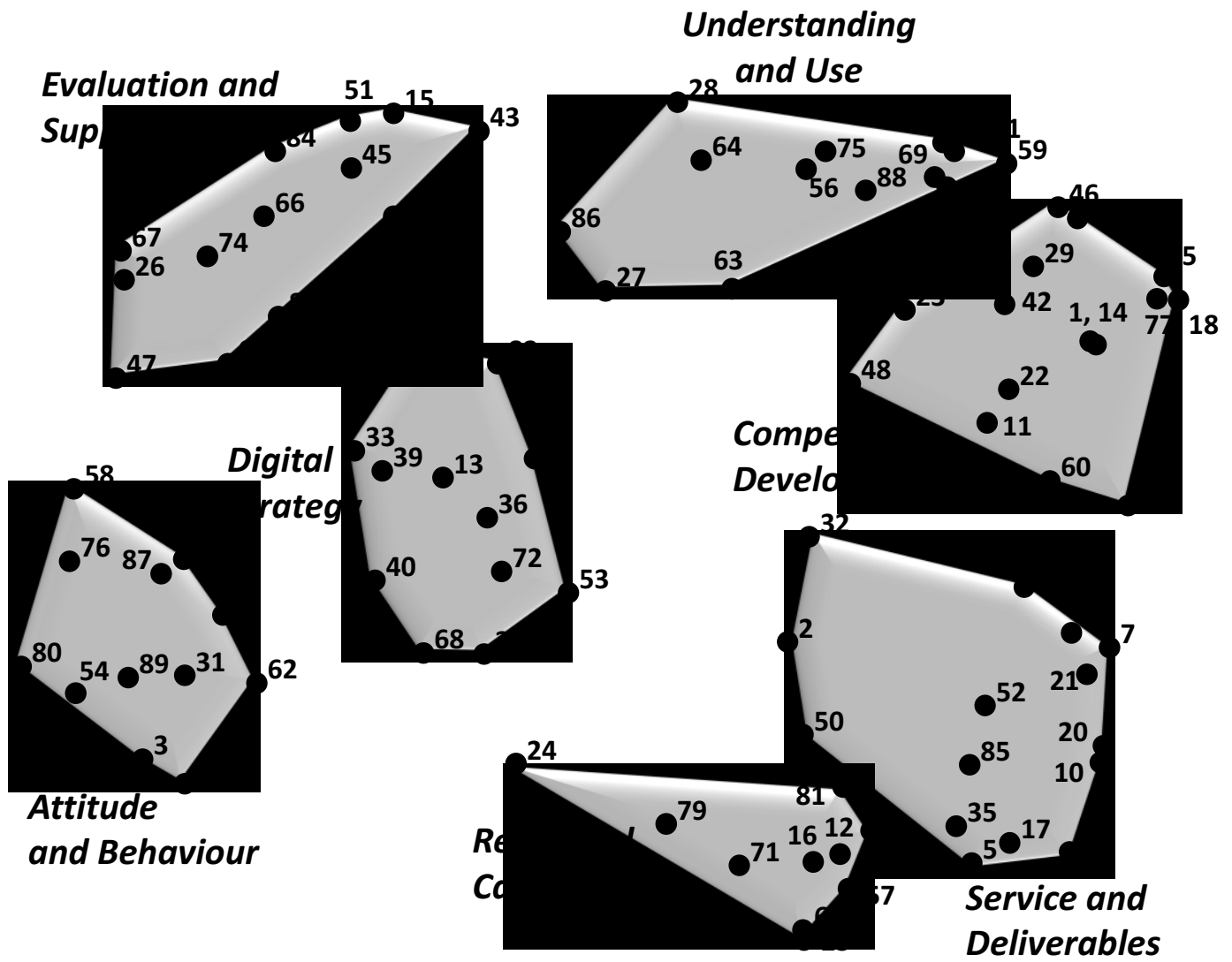

The map shows that as part of their group representation, entrepreneurs have placed the Digital Strategy, a well-anchored cluster $(\mathrm{ABI}=0.29)$ that includes 12 items at the centre of the concept map. On this cluster, the item 'Reflect on the business objectives pursued with the digital launch of the company' [item 13] is at the centre of the overall map. Other

\footnotetext{
${ }^{2}$ A battery of internal reliability measures were obtained and fared well within accepted ranges (Rosas and Kane, 2012).
} 
items describe dimensions such as setting IT objectives in relation to revising business objectives [items 36, 53, 72]; invest in IT from a qualitative standpoint (purpose, timing) [items 39, 40, 68]; and taking the required time to determine the various options that meet the business strategic objectives [items $4,9,83$ ]. The concept map depicts a complex system (Trochim and Cabrera, 2005). From a systemic and complexity perspective, all other clusters on the map emerge from the centre of that system, which is considered a systemic "attractor", and go back to it (Kane and Trochim, 2007). This cluster shares a border with all other clusters located around it on the concept map, and as such, possess some overreaching commonalities. In general, the interpretation is the cluster at the centre of the map translates or "absorb" tensions from dynamic interactions among all clusters on the concept map. In particular, clusters are opposite ends of the map contain items which were seldom sorted together by participants and typically express conceptual tensions among them. For example, clusters Understanding and Use and Competence and Development, are opposite to the cluster Attitude and Behaviour. Similarly, the cluster Evaluation and Support is at the opposite end of the cluster Services and Deliverables.

A cluster is dedicated to the notion of IT Evaluation and Support that is considered a bridging concept $(\mathrm{ABI}=0.67)$ and includes 13 items. This cluster addresses all types of evaluation support needed, including: determination of the appropriate online marketing performance measures [items 45, 72,]; enterprise brand and image [item 41, 47]; online contents [items 15, 43, 67, 82, 84]; information updating [items 26, 51]; and striking the right balance in between IT usefulness and return on investment (ROI) [items 66, 74].

Services and Deliverables regarding IT, a 15-item cluster, is an anchor $(\mathrm{ABI}=0.45)$. This cluster highlights elements of communication about IT needs adapted to SMEs between entrepreneurs and IT professionals. Some items relate to: the need to establish and maintain transparent discussions between entrepreneurs and IT professionals regarding deliverables [items 5, 10,52]; the quality/price ratio for the type of business [items 50, 85]; simple language communication [items 17, 21]; and optimal service levels for a small business [items 7, 30, 32, 35, 44].

Relational Capital regarding IT, a 10-item cluster, is situated mid-range and is neither an anchoring nor a bridging concept $(\mathrm{ABI}=0.52)$. This cluster highlights elements of the relationships between entrepreneurs and IT professionals. Some items relate to: the need 
to establish and maintain a relationship between entrepreneurs and IT professionals regarding SMEs IT development and business support within the ecosystem [items 16, 71, 78]; relational trust development in between peers and third parties within the ecosystem [items 12, 57, 65]; and enterprise culture understanding [items 71, 81].

The IT Competence Development cluster has 15 items which describe the different types of training needed about IT, fulfilling both customized and general IT-related needs. A well-anchored concept $(\mathrm{ABI}=0.37)$, some of these relate to: general knowledge about IT [items 11, 29, 38, 42]; or more specific technical information about IT and underlying services [items 14, 48] which can be obtained from interactions and communications with socioeconomic support professionals [items $23,55,77$ ], and more formal training [items $1,38,46]$.

The IT Understanding and Use is a well-anchored cluster $(\mathrm{ABI}=0.34)$ of 13 items. Some items concern the choice of the appropriate IT application [item 56, 63, 69, 86] and the determination of the use of IT associated to specific business needs [items 27, 28, 50, $61,70,88]$; making sure legal and technical aspects are harmonised [items 64, 70]; and that metadata produced by IT applications are part of what needs to be managed [item 75].

Last, but fundamental, the IT-Related Attitude and Behaviour is a 12-item cluster, and is clearly a bridging concept $(\mathrm{ABI}=0.75)$ that includes dimensions such as the blurring of the frontier between the personal and the professional life and imperatives [items 19]; the need to dedicate more time to the passion underlying the business than to IT management [items 3, 31, 62]; social media management and crisis avoidance [items 58, 76]; and to set expectations at the appropriate level regarding the adoption and use of turnkey IT applications [items 8, 49, 54, 80, 87, 89].

\subsection{Pattern matches between actors' perception of relative importance and feasibility}

Given the concept map conceptualisations associated with turkey IT applications in the digital transformation process, the next question to ask concerns the perceived relative importance and relative feasibility of these dimensions in context. This is explored in GCM using pattern matches graphs as in figures 3 and 4 (see detailed results on a cluster basis in Table A1 for scale comparisons between relative importance and relative feasibility ratings and statistical significance). The purpose is to observe whether there is a correspondence 
among subgroup profiles regarding respective perceptions of relative importance and relative feasibility within their reach in a SME context regarding what can be achieved on a cluster basis. Pattern matches highlight comparisons across participants' subgroups to the study, that is, entrepreneurs, IT professionals, and socioeconomic support professionals.

The figure 3 presents and compares pattern matches regarding the relative importance of each cluster of the concept map among the subgroups, on the five-point scale.

Figure 3.

Pattern Matches Comparing Relative Importance for Small Business Entrepreneurs, IT Professionals, and Socioeconomic Support Professionals

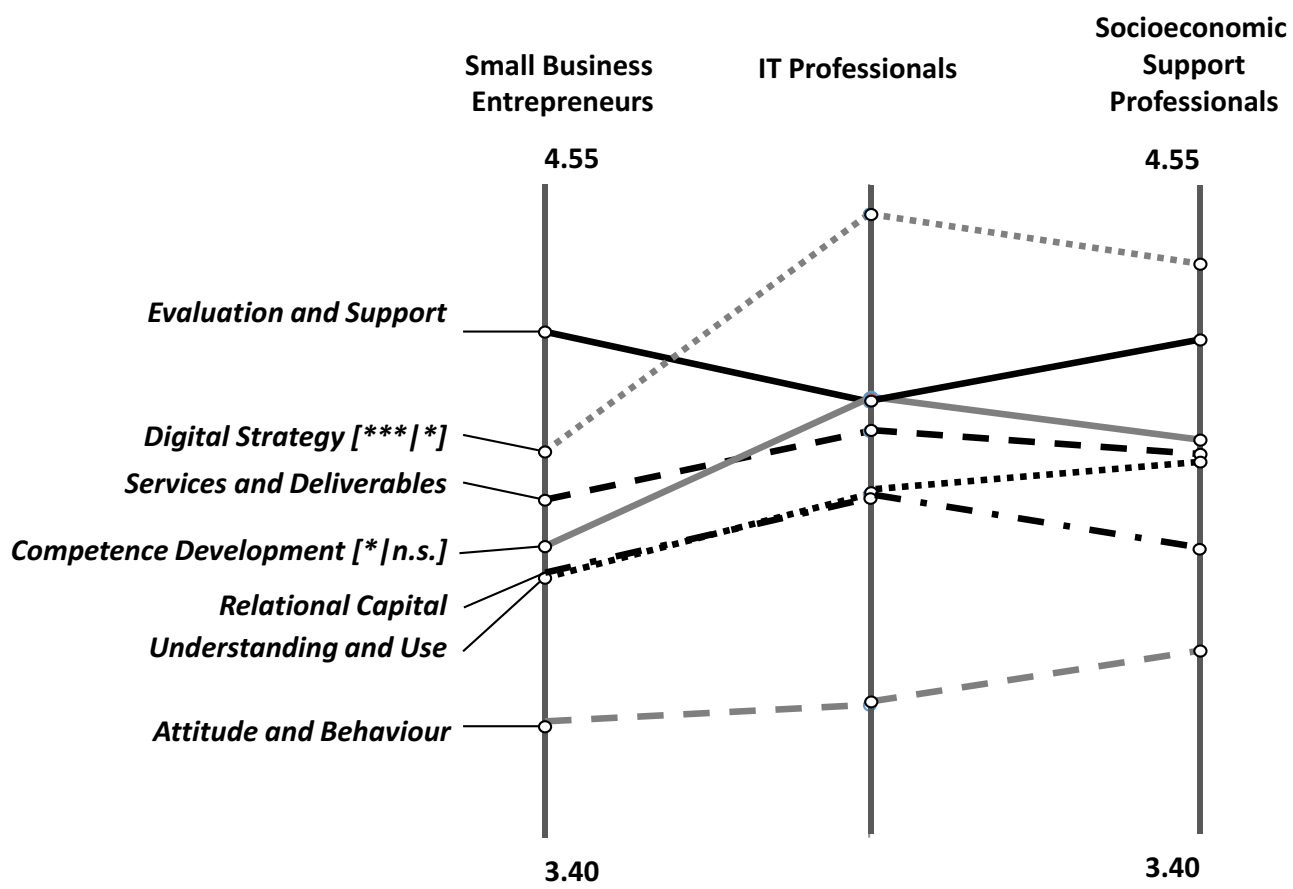

a Relative importance rating based on a 5-point Likert-type scale; Tests for statistical differences were conducted for each cluster to compare entrepreneurs and IT professionals, on the one hand (statistical significance reported on the left-hand side of the hard bracket), and entrepreneurs and socioeconomic support professionals, on the other hand ( $\rho$-value reported on the right-hand side of the hard bracket): * $\rho$ value $<0.05$; $* * *$-value $<0.005$; n.s.: not significant. The non-parametric Kruskal-Wallis Rank-order test for independent measures across profiles indicates no statistical difference for the relative importance scale $(\rho$-value $>0.05)$ between entrepreneurs, IT professionals, and socioeconomic support professionals.

A Kruskal-Wallis non-parametric test was conducted to examine the overall differences in ranking among profiles as far as relative importance of actions regarding the adoption and use of IT turnkey applications in digital transformation, and turned out not significant. This implies that overall, the relative importance, is considered similar among the three 
subgroups of participants to the study. There are, nonetheless, a few distinguishing features in this pattern matches in figure 3. First, the entrepreneurs rated first the IT Evaluation and Support cluster, while IT professionals and socioeconomic support professionals both perceived the Digital Strategy cluster as relatively more important than any other dimension to be addressed. Indeed, both IT professionals and socioeconomic support professionals considered that the Digital Strategy cluster ought to be the top priority, and this difference is statistically significant. Second, the Competence Development cluster was rated much lower by entrepreneurs and that perception is statistically significant when compared with IT professionals' perception of competences possessed by entrepreneurs. It would be interesting to further investigate why all participants' profiles have rated, as relatively low importance relative to IT adoption and use, clusters Relational Capital, and Understanding and Use.

The pattern matches regarding the relative feasibility of each cluster of the concept map among the three subgroups, on the five-point scale, is shown in figure 4, and the KruskalWallis Rank-order non-parametric test for independent measures is statistically significant. This indicates that participants do not hold the same perception as to the relative feasibility of actions concerning turnkey IT application adoption and use in digital transformation.

\section{Figure 4.}

Pattern Matches Comparing Relative Feasibility for Small Business Entrepreneurs, IT Professionals, and Socioeconomic Support Professionals 


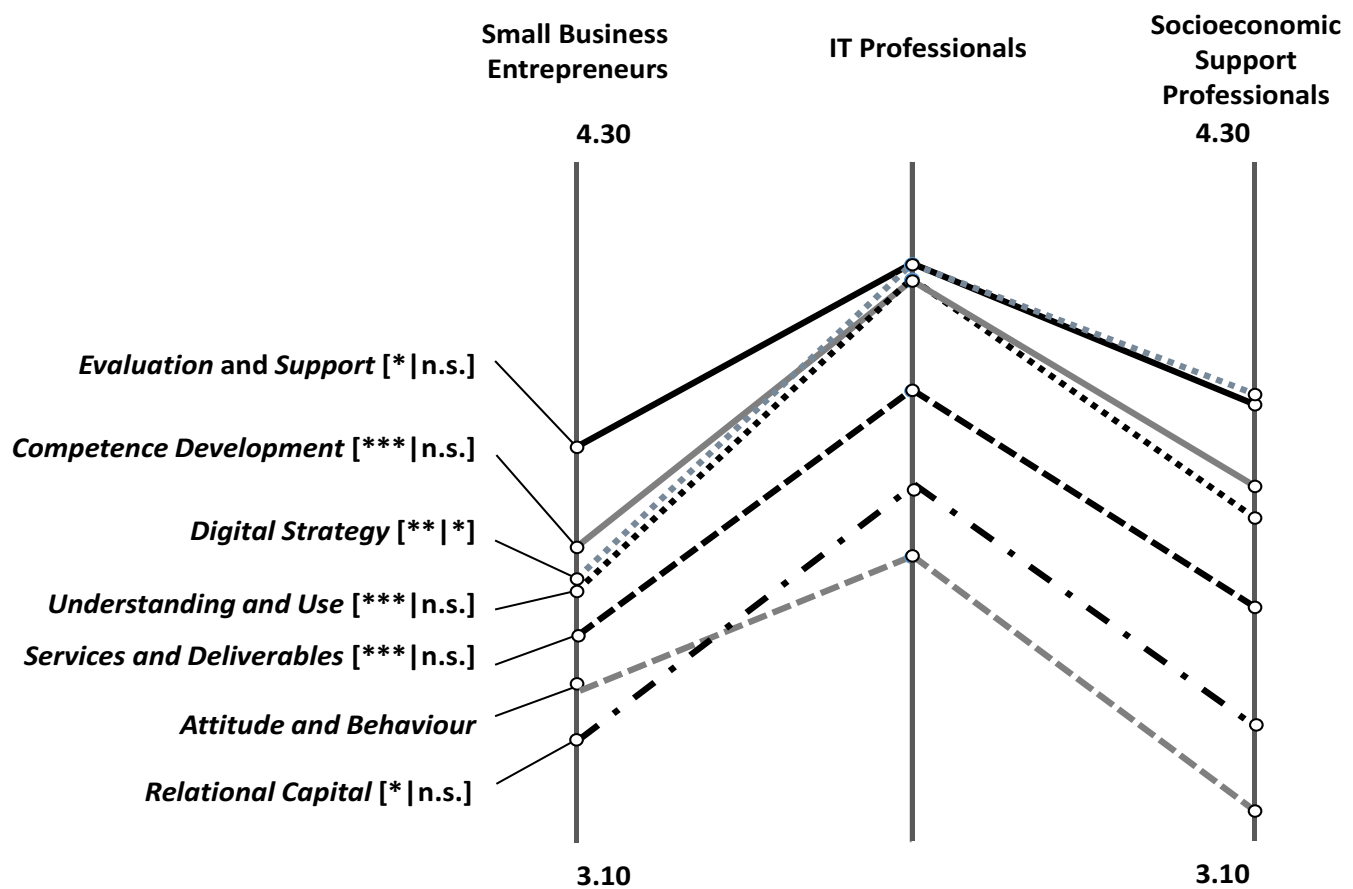

${ }^{a}$ Relative feasibility ratings based on a 5-point Likert-type scale; Tests for statistical differences were conducted for each cluster to compare entrepreneurs and IT professionals, on the one hand (statistical significance reported on the left-hand side of the hard bracket), and entrepreneurs and socioeconomic support professionals, on the other hand ( $\rho$-value reported on the right-hand side of the hard bracket):* $\rho$-value $<0.05$; $* * \rho$-value $<0.01 ; * * * \rho$-value $<0.001$; n.s.: not significant. The non-parametric Kruskal-Wallis rank-order test for independent measures indicates a significant statistical difference $(\rho$-value $<0.05)$ for the relative feasibility between entrepreneurs, IT professionals, and socioeconomic support professionals.

More specifically, on a cluster basis, there is more to say about the comparison among the three subgroups. Overall, there is little significant differences between entrepreneurs and socioeconomic support professionals regarding their respective perception of relative feasibility of action in each cluster, except regarding Digital Strategy, which entrepreneurs consider relatively less feasible. However, there is much statistical difference in between entrepreneurs and IT professionals for all clusters but Attitude and Behaviour. Among the highly feasible clusters Evaluation and Support and Competence Development occupy the first and second rank, respectively, while among moderately feasible are Digital Strategy and Understanding and Use. It is noteworthy that IT professionals consider these four clusters to be extremely feasible, hence, apparently not being aware of challenges associated with IT turnkey application adoption and use in digital transformation among entrepreneurs, unlike rating results shown on the part of socioeconomic support professionals. 


\section{Discussion}

This study aims to explore how three subgroups of actors interacting in a service ecosystem perceive and assess challenges of digital transformation when adopting and using turnkey IT applications. Previous results have proposed two levels of answers. First, it consists in defining with precision challenges of digital transformation, as represented by entrepreneurs working in smaller SMEs. The dimensions to these challenges were conceptualised and mapped in figure 2. Second, the extent to which these challenges are assessed regarding their relative importance as well as their relative feasibility by these actors interacting in the same ecosystem. Convergent and divergent elements about these observations were highlighted in figures 3 and 4 .

What is now raised by the discussion of these results refers to a third level of the answer, and that is: why does this situation occur? And what should we know about it? Especially, because these subgroups of actors are, in principle, dedicated to the same objective which is to develop and support SMEs through their respective strengths (e.g. entrepreneurship, technical skills, management support) (Roundy and Fayard, 2018). Indeed, results highlight how challenges and issues regarding digital transformation are perceived and evaluated in different ways, depending upon one's position in the ecosystem (i.e., entrepreneurs, IT professionals, socioeconomic support professionals). Thus, despite the observation of disparities among actors in such a situation which have already been documented in the IS/IT literature over the time, other factors, and intangible ones more than others, have clearly emerged considering results of this study. This is especially relevant given the work to be done to ensure digital transformation actors can achieve more effective communication exchanges that will, in turn, support more fruitful relationships to sustain competitiveness (Dyer and Kale, 2007), including innovation in their respective service offers (Barrett et al., 2015).

To explore this avenue, the strategic action go-zone graph shown in figure 5, displays a matrix displaying the relative importance/feasibility ratings for each cluster identified on the concept map. But, before going further, recall that following Dulipovici and Robey (2013), any representation is characterised by three elements: (1) The object that is represented (dimensions of the digital transformation); (2) The individual who builds the 
representation (entrepreneurs or IT professionals or socioeconomic support professionals); and (3) The group to which these individuals belong (a service ecosystem dedicated to SMEs) (p. 107).

Figure 5.

Entrepreneurs' Strategic Action Go-Zones

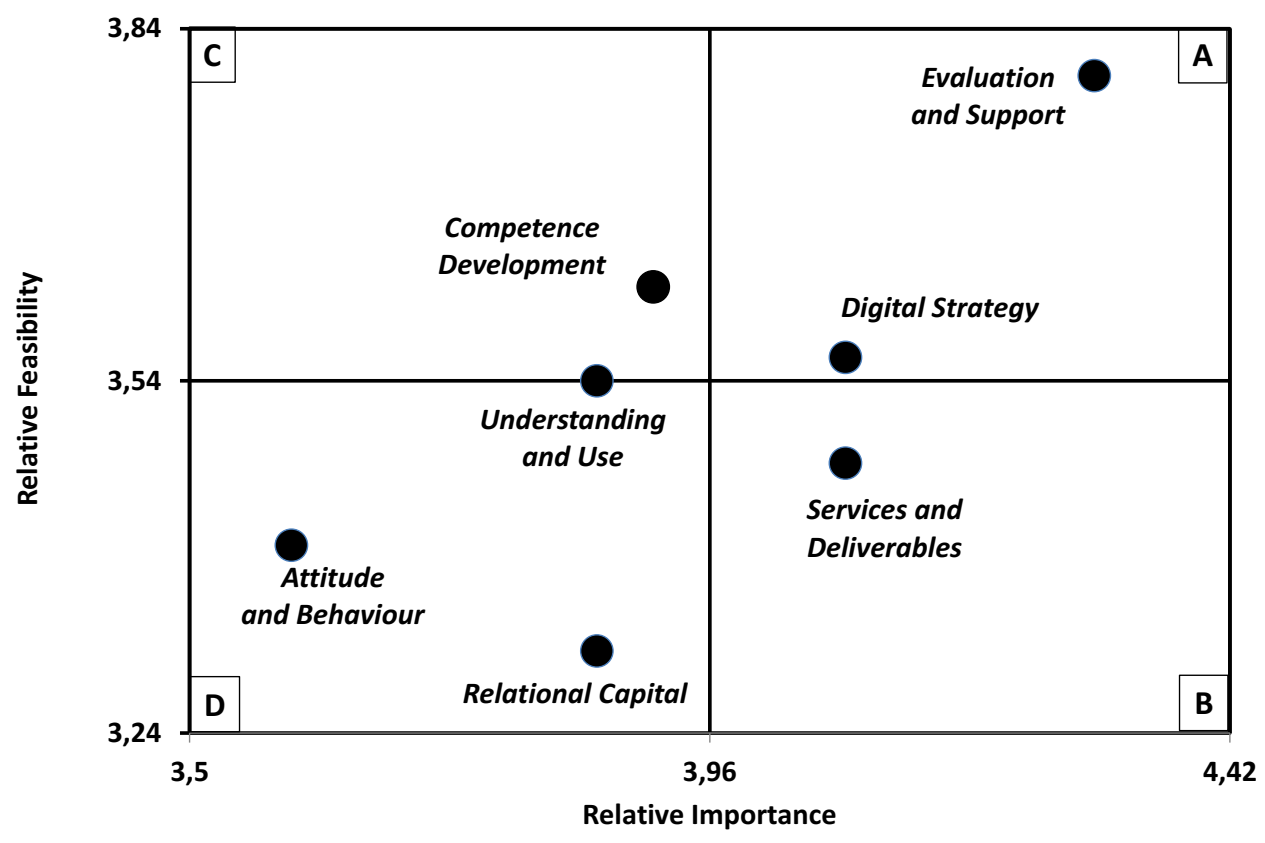

As seen in the quadrant A, for entrepreneurs, the Evaluation and Support and Digital Strategy fall within the relatively important and relatively feasible zone in the context of this research. Given turnkey IT applications are usually offered through a service-oriented architecture (SOA) (Bradley et al., 2011) within which companies can access different features and option sets at various costs, prior studies are clear about two aspects. First, SMEs often achieve mixed results because IT value creation is way more difficult than anticipated at the onset by entrepreneurs and managers. Second, digital transformation is much more than a simple technology choice at a given time (Celuch et al., 2007; Dulipovici and Robey, 2013; Matt et al., 2015). Following the situation examined and well documented in the literature dedicated to IS/IT in SMEs (Celuch et al., 2007; Levy et al., 2011; Pelletier and Raymond, 2017; Street et al., accepted), there are several explanations for this. First, the difficulty for SMEs to achieve a strategic IT alignment through technology choices consistent with business objectives. Second, a one-size-fits-all 
approach to the adoption and use of IT that does not take into account specific needs and expectations of entrepreneurs and SMEs, as well as their specific characteristics and contingencies from the environment. Third, an operation focus that is short term-oriented. Fourth, a limited perception of IT potential as a "commodity". Fifth, an informal management practice that restricts the use of IT for greater strategic purpose. Finally, a business context within which it is not uncommon for IT resources and technological competences to be underestimated, poorly perceived and presented, idealised, fragmented or simply misunderstood by entrepreneurs and managers as well as by internal and external actors. The question about this quadrant now is: do entrepreneurs confuse digital strategy and simple choice of technology? A confusion that does not seem to concern the other two actor subgroups.

Coherent with a possible confusion about what a digital strategy really is (Matt et al., 2015), the Services and Deliverables cluster, in the quadrant B, is considered as important as the Digital Strategy, however, considered relatively less feasible. Recall that Services and Deliverables is an anchor cluster that is related to issues of communication about IT needs adapted to SMEs between entrepreneurs and IT specialists regarding IT specifications, the quality/price ratio, and the simplicity of language in communication to ensure the appropriate service level to meet SME needs. Thus, SMEs have access to turnkey IT applications that support a number of business functions (e.g. Google Analytics for marketing; Amazon, PayPal for e-commerce or other social media solutions, including Facebook which offers a range of features for SMEs; Skype, Teamviewer and Messenger for collaboration, etc.). Nevertheless, and similarly as what was observed in the quadrant A, as useful and necessary as they appear at first glance, the adoption and use of these IT applications by SMEs pose significant challenges to strategies and processes they require upfront (Neirotti et al., 2018). Thus, emerging needs include indispensable relationships with IT professionals and different service providers, such as socioeconomic support professionals. Moreover, exchanges between actors could at times be difficult, given the lack of shared terminology and language (Amiri et al., 2015), mutual understanding of priorities regarding IT acquisition (Oney et al., 2018), or even a common understanding of business issues and needs (Preston and Karahanna, 2009; Reich and Benbasat, 2000). This was somehow clear during the group discussions which have allowed the primary content 
data collection about ideas (Section 3, GCM Step 2). Hence, results highlight there is a common thread to the three subgroups of actors examined regarding technology adoption, use and change. In short, although interactions are growing between actors, communications, as much as service exchange, are still struggling to be established in ways that are really rooted in the recommended sociotechnical approach to IS/IT (Besson and Rowe, 2012; Dyer and Kale, 2007), including the digital transformation process (Matt et al., 2015; Oney et al., 2018).

In quadrant $\mathrm{C}$, entrepreneurs consider the Competence Development cluster as relatively more feasible, although relatively less important, as is, for Understanding and Use. This situation can be explained for SMEs facing IT issues that the ecosystem is of paramount importance (Levy et al., 2011). There is one main reason for this: A digital transformation process raises important questions on the part of entrepreneurs on both personal and social dimensions which are important to the enterprise (Zollo et al., 2016). More specifically, in such a situation, entrepreneurs are faced with the need to divert their attention away from a product or service process that occupies a significant part of their time, to set up and manage new ones, such as non-existent structures or new relationships induced by turnkey IT application adoption and use (Barrett et al., 2015; Gottschalg and Zollo, 2007). In such situations, developing IT competencies and their management can be perceived as a distraction and a waste of time, especially, if there are competent IT professionals available to do the work. Nevertheless, this attitude poses a problem if we consider that in a service ecosystem based on an S-D logic (Pelletier and Raymond, 2017), the added value for the enterprise is created mainly by relationships established on a free-form basis rather than based on a vertical chain of command (Vargo and Lusch, 2011). However, this interpretation is not that surprising given the emphasis shown in the quadrant $\mathrm{D}$ for Attitude and Behaviour and Relational Capital.

The quadrant D concerns the cluster Relational Capital, which is really important for a performing SMEs within the ecosystem (Dyer and Kale, 2007). It also concerns Attitude and Behaviour toward IT. Both fall within the relatively less important and feasible zone ${ }^{3}$.

\footnotetext{
${ }^{3}$ The interested reader can consult the table A1 in the Appendix which exhibits detailed results for each subgroup of participants in addition to statistical differences among them for both relative importance and relative feasibility scales. In general, except for one cluster in each case (Attitude and Behaviour for entrepreneurs, and Relational Capital for socioeconomic professionals), entrepreneurs exhibit results similar
} 
Nevertheless, one of the very well-documented challenges for adopting, using and managing IT applications in SMEs, is the struggle to assess IT needs, as much as contingencies to which they are exposed. This reminder is important considering that, from a relational view, to generate a real competitive advantage four conditions must be met by its actors: (1) To invest in specific relationship-type assets, hence the use of turnkey IT applications designed and developed outside the enterprise; (2) To have an exchange of knowledge through collaborations or services which extend beyond enterprise boundaries; (3) To combine resources and capabilities into inimitable assets, which respect the idiosyncrasy of SME needs to offer differentiated products/services to various markets based on different strategies; and (4) To lower transaction costs through "unified" governance with socioeconomic actors called in to play a new role as digital support professionals (Dyer and Kale, 2007). For instance, this is accomplished through interventions which cover both explicit (information) and tacit (know-how) IT components (Grant, 1996). Finally, given S-D logic principles, this situation means the ecosystem has an urgent need to work on: (1) The service as a sound basis of exchanges; (2) The more complete understanding of value cocreation by multiple actors; (3) The integration of resources by all social and economic actors; (4) The value that is determined by the beneficiary, and (5) The value cocreation that is coordinated through "shared institutions" (e.g. social norms, rules, symbols and other normative and heuristic guidelines) (Ng and Vargo, 2018; Vargo and Lusch, 2011, 2016a). To summarise, given the specific needs that have emerged, it is now necessary to give an increased importance to intangible dimensions of digital transformation, which are encompassed by items in Attitude and Behaviour as well as Relational Capital clusters. This, even if these clusters appear to be perceived as neither important nor feasible for the three subgroups of actors.

Regarding entrepreneurs, figures 2 and 5 allow to propose a more accurate conceptualisation of what is happening in the entrepreneurs' subgroup more specifically. Now, how are the two other subgroups concerned about the situation that has been brought to light? For IT professionals in particular, this means that it will be important to be

to socioeconomic IT professionals, regarding statistical difference between the two scales, while IT professional results show no statistical difference across clusters, except for Digital Strategy (which is not their concern). 
cognisant of two factors: (1) The "dependence" of SMEs on their products and services will vary greatly based on their specific needs (Levy et al., 2011), and (2) The concrete (or not) contribution of IT to the competitive advantage of some SMEs (Matt et al., 2015). In other words, are turnkey IT applications adopted and implemented by SMEs complementary resources of a strategic nature for intra or inter-organisational service innovation? (Barrett et al., 2015); or are they for additional organisational resources? (Dyer and Kale, 2007); or are they simple operational commodities? (Celuch et al., 2007). The anticipated answer to these questions is also central to explaining priority differences highlighted between the relative importance of issues identified by entrepreneurs, IT professionals and socioeconomic support professionals. For socioeconomic support professionals, and despite the obvious avoidance for addressing these issues during the group discussion (Section 3, GCM Step 2), the results precisely target the importance of social interactions and user perceptions when facing technological and digital development, including the implementation and/or adoption and use of existing IT (Dulipovici and Robey, 2013).

\section{Implications and conclusion}

Concerning Entrepreneurs' Strategic Action Go-Zones (Figure 5), one of the first

observations that emerges from the results is related to the fundamental quest of "IT alignment" to ensure the actual as well as the future coherence concerning technological choices carried out by smaller enterprises (Pelletier and Raymond, 2017). For example, results have revealed questionable motivations at times on the part of entrepreneurs and SMEs to adopt and use turnkey IT applications rather than custom developed ones. Thus, from the data obtained during the first group discussion with entrepreneurs, it became clear that the widespread adoption and use of turnkey IT applications were much more motivated by limited resources (human, material and financial) than a genuine strategic intent. Hence, the confirmation a continuous focus on turnkey IT applications is utmost relevant (e.g. social media, e-commerce platforms, mobile payment, online collaborative applications, etc.).

In doing so, it was also expected the usual critical success factors regarding IT applications / software also applied, and this was the situation observed. Following Grant's 
works concerning knowledge management (1996), in this situation, socioeconomic support professionals could act as a catalyst between SMEs and IT professionals when sharing knowledge, even if the environment remains dynamic. This could be done by developing / offering and/or financing custom training / coaching sessions dedicated to specific challenges of smallest SMEs concerning the adoption and use of IT, be it turnkey application and/or other type of applications and software. As seen, a successful and consistent digital transformation requires investing not only in IT artefacts and infrastructure (e.g. hardware, software, networks, etc.) (Besson and Rowe, 2012; Bradley et al., 2011), but also in strategic, intellectual, structural, formal and informal, social and cultural dimensions (Chan and Reich, 2007).

\subsection{Implications for practice}

On the practical front and to complete previous observations concerning the evolving roles of the three profiles of actors studied, the research contributes to the awareness, and offers a broader reflection about IT and digital transformation challenges. First, at the attention of entrepreneurs in the SME context who ought to consider evidence-based recommendations as well as critical success factors regarding IT applications / software motivation in adoption and use, as well as choice. For example, this may include: a consistent management support through adequate resources allocation, the offer of various learning activities, the encouragement to constant experimentation with IT, the development of long-term specialised partnerships (Pelletier and Raymond, 2017). Second, for IT professionals, the sharing and transfer of knowledge among participants to the identified challenges of using turnkey IT applications already suggests the importance of developing and using a more common vocabulary and a language that is closer to the business management going concerns (Amiri et al., 2015; Preston and Karahanna, 2009). Third, for socioeconomic support professionals, the aim is to be in a better position to develop programs which support the digital shift with interventions focused on similarities and differences that emerge among SMEs (Vargo and Lusch, 2011), and this, whether they are working in different business sectors, they already use turnkey TI applications or simply anticipate doing so. 
Further analysis of issues already identified could focus on understanding established relationships as well as desirable behaviours and decision-making principles for all actors in the ecosystem examined (Barrett et al., 2015; Tsujimoto et al., 2018). There is another objective for researchers as well as for the whole SMEs' ecosystem and its actors, that is, a real improvement in support (public and private) for entrepreneurs and SMEs. First, through complementary forces tied among each other (Roundy and Fayard, 2018). Second, by the recognition that digital transformation is, before everything, a social process that materialises through aspects other than a simple IT artefact evaluation, adoption and use (Besson and Rowe, 2012; Matt et al., 2015; Oney et al., 2018). To do so, policymakers could use the present study and conceptual representations to further develop and strengthen the IT-related support agenda for "Digital Transformation of SMEs", especially the smaller ones. This could be done through customised training programs, support and coaching initiatives, etc. However, as seen, this includes an in-depth investigation of items found in two clusters which concern Attitude and Behaviour regarding IT and the development of Relational Capital.

\subsection{Implications for theory}

The GCM approach used in this exploratory study helped to better delineate efforts required by three subgroups of actors in a service ecosystem primarily dedicated to SMEs. As a result, actors are better able to put into place mechanisms to accurately assess the actual contribution of turnkey IT applications. In this regard, results underscored by the methodological approach taken highlight the importance to better understanding relational, social and cognitive aspects underlying the fruitful exchanges of knowledge between actors (Dulipovici and Robey, 2013; Grant, 1996).

Based on perception measures obtained from three groups of actors of a service ecosystem whose main activities are dedicated to SMEs, the theoretical contributions of the research allow for a more precise identification of issues facing SMEs in turnkey IT applications adoption and use. In doing so, the contribution of the GCM framework highlighted the complex interactions found in such a context. More specifically, given the growing interdependence and redefinition of relational and communication boundaries in the digital era (Barrett et al., 2015), the research contributions are threefold: (1) Identify 
needs in terms of human, financial and time resources that must be allocated by SMEs; (2) Define specific technical skills desirable in this context (Neirotti et al., 2018); and (3) Focus on the organisational and strategic capabilities which can be supported through better targeted decision-making in IT-oriented socioeconomic interventions (Tsujimoto et al., 2018).

To conclude, even if there is a sustained interest for the "who" approach in IS/IT-related research (Reich and Benbasat, 2000), it remains seldom used to study complex phenomena such as digital transformation (Besson and Rowe, 2012; Zollo et al., 2016). The digital transformation is accelerating and has implications for all actors concerned, and especially for entrepreneurs who perceive and understand the situation and its challenges in multiple ways (Gottschalg and Zollo, 2007; Vargo and Lusch, 2011). Although promising for the digital transformation of SMEs, the growing universe of IT applications of all kinds, including existing turnkey IT applications, requires significant efforts on the part of actors generally not equipped to cope with business, technological and managerial requirements. It would be simple to consider that for IT professionals and socioeconomic professionals' challenges are different, but this is not so. Even if the usual critical success factors regarding other types of IT applications would also apply to the context of turnkey IT applications / software, this situation is also challenging for IT and socioeconomic support professionals given intervention support programs address distinctive services offered to SMEs. In any case, results of this study startlingly show the need for better targeted interventions, that is, services that cover the intellectual (knowledge), social (mutual commitment) and relational (transfer) dimensions required to ensure greater long-term technological and strategic coherence (Chan and Reich, 2007; Reich and Benbasat, 2000).

\section{References}

Amiri, A. K., H. Cavusoglu, and I. Benbasat. (2015), "Enhancing strategic IT alignment through common language: Using the terminology of the resource-based view or the capability-based view?", in 36th International Conference on Information Systems (ICIS), Fort Worth, Texas, USA.

Barrett, M., E. Davidson, J. Prabhu, and S. L. Vargo. (2015), "Service innovation in the digital age: Key contributions and future directions", MIS Quarterly, Vol. 39 No. 1, pp. 135-154.

Berg, S., L. Cloutier, and S. Bröring. (2018), "Collective stakeholder representations and perceptions of drivers of novel biomass-based value chains". Journal of Cleaner Production, Vol. 200, pp. 231-241. 
Besson, P., and F. Rowe. (2012), "Strategizing information systems-enabled organizational transformation: A transdisciplinary review and new directions", The Journal of Strategic Information Systems, Vol. 21 No. 2, pp. 103-124.

Bradley, R. V., R. M. Pratt, T. A. Byrd, and L. Simmons. (2011), "The role of enterprise architecture in the quest for IT value", MIS Quarterly Executive, Vol. 10 No. 2, pp. 19-27.

Celuch, K., G. B. Murphy, and S. K. Callaway. (2007), "More bang for your buck: Small firms and the importance of aligned information technology capabilities and strategic flexibility", The Journal of High Technology Management Research, Vol. 17 No. 2, pp. 187-197.

Chan, Y., and B. Reich. (2007), "IT alignment: What have we learned?", Journal of Information Technology, Vol. 22, pp. 297-315.

Cloutier, L. M., S. Arcand, E. M. Laviolette, and L. Renard. (2017), "Collective economic conceptualization of strategic actions by Québec cidermakers: A mixed methods-based approach", Journal of Wine Economics, Vol. 12 No. 4, pp. 405-415.

Cloutier, L. M., S. Cueille, and G. Recasens (2017), Entrepreneurs' perspectives on the structuring of the phase of the entrepreneurial team. in C. Ben-Hafaïedh and Cooney, T. M. (Eds.), Research Handbook on Entrepreneurial Teams: Theory and Practice: Edward Elgar Publishing, (pp. 96-120).

Cloutier, L. M., and M. P. Spooner (2016), Closing gaps in professional service delivery processes: A mixed method-based analysis of clinical research project budget management, in C. Di Mauro, Ancarani, A., Vastag, G. (Eds.), Research in the Decision Sciences for the Service Economy: Pearson Education Inc., (pp. 32-52).

Dulipovici, A., and D. Robey. (2013), "Strategic alignment and misalignment of knowledge management systems: A social representation perspective", Journal of Management Information Systems, Vol. 29 No. 4, pp. 103-126.

Dyer, J. H., and P. Kale (2007), Relational capabilities: Drivers and Implications, in Helfat, C. E. (dir.). Dynamic Capabilities Understanding Strategic Change in Organizations, UK: Blackwell Publishing, (pp. 65-79).

Everitt, B. S., S. Landau, M. Leese, and D. Stahl (2011), Cluster Analysis, (5 ed.), Chischester, UK: John Wiley \& Sons.

Fujita, S., C. Vaughan, and S. Vargo. (2018), "Service ecosystem emergence from primitive actors in service dominant logic: An exploratory simulation study", in 51st Hawaii International Conference on System Sciences (HICSS), Big Island, Hawaii, USA.

Gottschalg, O., and M. Zollo. (2007), "Interest alignment and competitive advantage", Academy of Management Review, Vol. 32 No. 2, pp. 418-437.

Grant, R. M. (1996), "Prospering in dynamically-competitive environments: Organizational capability as knowledge integration", Organization Science, Vol. 7 No. 4, pp. 375-387.

Gregory, R. W., M. Keil, J. Muntermann, and M. Mähring. (2015), "Paradoxes and the nature of ambidexterity in IT transformation programs", Information Systems Research, Vol. 26 No. 1, pp. 57-80.

Innovation, Science and Economic Development of Canada (ISED). (2019), "Key Small Business Statistics - January 2019", available at https://www.ic.gc.ca/eic/site/061.nsf/vwapj/KSBSPSRPE_Jan_2019 eng.pdf/\$file/KSBS-PSRPE_Jan_2019 eng.pdf (accessed 25-04-2019).

Kane, M., and S. Rosas (2018), Conversations About Group Concept Mapping: Applications, Examples, and Enhancements, Thousand Oaks, CA, USA SAGE Publications.

Kane, M., and W. M. Trochim (2007), Concept mapping for planning and evaluation, Thousand Oaks, CA, USA: SAGE Publications.

Kelly, S., and D. Scott. (2012), "Relationship benefits: Conceptualization and measurement in a business-to-business environment", International Small Business Journal, Vol. 30 No. 3, pp. 310-339. 
Kilubi, I., and N. O'Regan. (2016), "Strategic technology partnering capabilities: A systematic review of the empirical evidence over two decades", Journal of Strategy and Management, Vol. 9 No. 2, pp. 216-255.

Kruskal, J. B., and M. Wish (1978), Multidimensional Scaling, Thousand Oaks, CA, USA: SAGE Publications.

Levy, M., P. Powell, and P. Yetton. (2011), "Contingent dynamics of IS strategic alignment in small and medium-sized enterprises", Journal of Systems and Information Technology, Vol. 13 No. 2, pp. 106-124.

Matt, C., T. Hess, and A. Benlian. (2015), "Digital transformation strategies", Business \& Information Systems Engineering, Vol. 57 No. 5, pp. 339-343.

Neirotti, P., E. Raguseo, and E. Paolucci. (2018), "How SMEs develop ICT-based capabilities in response to their environment: Past evidence and implications for the uptake of the new ICT paradigm", Journal of Enterprise Information Management, Vol. 31 No. 1, pp. 10-37.

$\mathrm{Ng}$, I. C., and S. L. Vargo. (2018), "Service-dominant (SD) logic, service ecosystems and institutions: bridging theory and practice", Journal of Service Management, Vol. 29 No. 4, pp. 518-520.

OECD. (2017), "OECD Digital Economy Outlook 2017", available at https://www.oecdilibrary.org/science-and-technology/oecd-digital-economy-outlook-2017_9789264276284-en (accessed 03-09-2018).

Oney, C., G. Özdinç, and S. Çavuşyan. (2018), "Digital transformation: A mutual understanding and strategic alignment perspective", in 39th International Conference on Information Systems (ICIS), San Francisco, USA.

Pelletier, C., and L. Raymond. (2017). "Dynamic capabilities-based view of the IT alignment process: A multiple case study of SMEs in the industrial service sector", in Annual Conference of Administrative Sciences Association of Canada (ASAC) - Information systems (IS) division, Montréal, Québec, Canada.

Preston, D., and E. Karahanna. (2009), "How to develop a shared vision: The key to IS strategic alignment", MIS Quarterly Executive, Vol. 8 No. 1, pp. 1-8.

Reich, B. H., and I. Benbasat. (2000), "Factors that influence the social dimension of alignment between business and information technology objectives", MIS Quarterly, Vol. 24 No. 1, pp. 81-113.

Rosas, S. R. (2017), "Group concept mapping methodology: Toward an epistemology of group conceptualization, complexity, and emergence", Quality \& Quantity, Vol. 51 No. 3, pp. 1403-1416.

Rosas, S. R., and M. Kane. (2012), "Quality and rigor of the concept mapping methodology: A pooled study analysis", Evaluation and Program Planning, Vol. 35 No. 2, pp. 236-245.

Roundy, P. T., and D. Fayard. (2018), "Dynamic capabilities and entrepreneurial ecosystems: The micro-foundations of regional entrepreneurship", The Journal of Entrepreneurship, pp. 1-27.

Street, C., B. Gallupe, and J. Baker. (accepted), "Strategic alignment in SMEs: Strengthening theoretical foundations", Communications of the Association for Information Systems, Vol. 34.

Sutherland, S., and S. Katz. (2005), "Concept mapping methodology: A catalyst for organizational learning", Evaluation and Program Planning, Vol. 28 No. 3, pp. 257-269.

Tan, F. B., and R. B. Gallupe. (2006), "Aligning business and information systems thinking: A cognitive approach", IEEE Transactions on Engineering Management, Vol. 53 No. 2, pp. 223-237.

Thorpe, R., R. Holt, A. Macpherson, and L. Pittaway. (2005), "Using knowledge within small and medium- sized firms: a systematic review of the evidence", International Journal of Management Reviews, Vol. 7 No. 4, pp. 257-281.

Trochim, W. M. (2017), "Hindsight is 20/20: Reflections on the evolution of concept mapping", Evaluation and Program Planning, Vol. 60, pp. 176-185. 
Trochim, W. M. K., and D. Cabrera. (2005), "The complexity of concept mapping for policy analysis", Emergence: Complexity \& Organization, Vol. 7 No. 1, pp. 11-22.

Tsujimoto, M., Y. Kajikawa, J. Tomita, and Y. Matsumoto. (2018), "A review of the ecosystem concept - towards coherent ecosystem design", Technological Forecasting and Social Change, Vol. 136, pp. 49-58.

Vargo, S. L., and R. F. Lusch. (2008), "Service-dominant logic: continuing the evolution", Journal of the Academy of marketing Science, Vol. 36 No. 1, pp. 1-10.

Vargo, S. L., and R. F. Lusch. (2011), "It's all B2B... and beyond: Toward a systems perspective of the market", Industrial Marketing Management, Vol. 40 No. 2, pp. 181-187.

Vargo, S. L., and R. F. Lusch. (2016a), "Institutions and axioms: An extension and update of service-dominant logic", Journal of the Academy of marketing Science, Vol. 44 No. 1, pp. 5-23.

Vargo, S. L., and R. F. Lusch. (2016b), "Service-dominant logic 2025", International Journal of Research in Marketing, Vol. 34, pp. 46-67.

Weick, K. E. (1995), Sensemaking in Organizations, Thousand Oaks, CA: Sage Publications.

Zollo, M., E. L. Bettinazzi, K. Neumann, and P. Snoeren. (2016), "Toward a comprehensive model of organizational evolution: Dynamic capabilities for innovation and adaptation of the enterprise model", Global Strategy Journal, Vol. 6 No. 3, pp. 225-244. 


\section{Appendix}

Table A1.

Entrepreneurs, IT Professionals, and Socioeconomic Support Professionals: Relative Importance and Relative Feasibility by Dimension

\begin{tabular}{|c|c|c|c|c|c|c|}
\hline \multirow{2}{*}{$\begin{array}{l}\text { Entrepreneurs } \\
\text { Dimension }^{\dagger}\end{array}$} & \multicolumn{2}{|c|}{$\begin{array}{l}\text { Importance } \\
\text { rating }\end{array}$} & \multicolumn{2}{|c|}{$\begin{array}{l}\text { Feasibility } \\
\text { rating }\end{array}$} & \multirow[t]{2}{*}{$r^{*}$} & \multirow[t]{2}{*}{$\begin{array}{l}\text { Statistical } \\
\text { Sig. }\end{array}$} \\
\hline & $\overline{x_{I}}$ & $S^{2}$ & $\bar{x}_{F}$ & $S^{2}$ & & \\
\hline Evaluation and Support & 4.30 & 0.07 & 3.80 & 0.10 & .77 & $\rho<0.001$ \\
\hline Digital Strategy & 4.08 & 0.14 & 3.56 & 0.11 & .77 & $\rho<0.005$ \\
\hline Services and Deliverables & 4.08 & 0.12 & 3.47 & 0.09 & .58 & $\rho<0.001$ \\
\hline Competence Development & 3.91 & 0.11 & 3.62 & 0.05 & .53 & $\rho<0.01$ \\
\hline Relational Capital & 3.86 & 0.13 & 3.31 & 0.11 & .64 & $\rho<0.005$ \\
\hline Understanding and Use & 3.86 & 0.12 & 3.54 & 0.09 & .60 & $\rho<0.05$ \\
\hline Attitude and Behaviour & 3.59 & 0.25 & 3.39 & 0.09 & .43 & $\rho>0.05$ \\
\hline \multirow{2}{*}{$\begin{array}{l}\text { IT Professionals } \\
\text { Dimension }\end{array}$} & \multicolumn{2}{|c|}{$\begin{array}{l}\text { Importance } \\
\text { rating }\end{array}$} & \multicolumn{2}{|c|}{$\begin{array}{l}\text { Feasibility } \\
\text { rating }\end{array}$} & \multirow[t]{2}{*}{$r^{*}$} & \multirow[t]{2}{*}{$\begin{array}{l}\text { Statistical } \\
\text { Sig. }\end{array}$} \\
\hline & $\overline{x_{I}}$ & $S^{2}$ & $\bar{x}_{F}$ & $S^{2}$ & & \\
\hline Digital Strategy & 4.51 & 0.05 & 4.13 & 0.08 & -.16 & $\rho<0.005$ \\
\hline Services and Deliverables & 4.21 & 0.12 & 4.01 & 0.04 & .11 & $\rho>0.05$ \\
\hline Competence Development & 4.18 & 0.11 & 4.10 & 0.06 & .55 & $\rho>0.05$ \\
\hline Evaluation and Support & 4.17 & 0.13 & 4.13 & 0.12 & .56 & $\rho>0.05$ \\
\hline Understanding and Use & 4.01 & 0.12 & 4.10 & 0.10 & .37 & $\rho>0.05$ \\
\hline Relational Capital & 3.98 & 0.04 & 3.73 & 0.23 & .75 & $\rho>0.05$ \\
\hline Attitude and Behaviour & 3.63 & 0.12 & 3.60 & 0.07 & .26 & $\rho>0.05$ \\
\hline $\begin{array}{l}\text { Socioeconomic } \\
\text { Support Professionals }\end{array}$ & \multicolumn{2}{|c|}{$\begin{array}{l}\text { Importance } \\
\text { rating }\end{array}$} & \multicolumn{2}{|c|}{$\begin{array}{l}\text { Feasibility } \\
\text { rating }\end{array}$} & $r^{*}$ & $\begin{array}{l}\text { Statistical } \\
\text { Sig. }\end{array}$ \\
\hline Dimension $^{\dagger}$ & $\overline{x_{I}}$ & $S^{2}$ & $\bar{x}_{F}$ & $S^{2}$ & & \\
\hline Digital Strategy & 4.42 & 0.05 & 3.89 & 0.03 & -.55 & $\rho<0.001$ \\
\hline Evaluation and Support & 4.28 & 0.14 & 3.87 & 0.10 & .68 & $\rho<0.001$ \\
\hline Services and Deliverables & 4.24 & 0.07 & 3.64 & 0.09 & .38 & $\rho<0.001$ \\
\hline Competence Development & 4.10 & 0.11 & 3.73 & 0.10 & .45 & $\rho<0.005$ \\
\hline Understanding and Use & 4.06 & 0.12 & 3.67 & 0.11 & .47 & $\rho<0.01$ \\
\hline Relational Capital & 3.82 & 0.29 & 3.32 & 0.22 & .46 & $\rho>0.05$ \\
\hline Attitude and Behaviour & 3.72 & 0.11 & 3.14 & 0.10 & .34 & $\rho<0.001$ \\
\hline
\end{tabular}

$*$ correlation; $\dagger$ Wilcoxon Signed-Rank Test $(\rho<0.01)$ for relative importance and feasibility ratings for entrepreneurs and socioeconomic support professionals. 